\title{
Electrochromic Nickel Oxide Films for Smart Window Applications
}

\author{
Michelle P. Browne*, Hugo Nolan, Nina C. Berner, Georg S. Duesberg, Paula E Colavita and Michael \\ E. G. Lyons ${ }^{*}$ \\ School of Chemistry and CRANN, Trinity College Dublin, The University of Dublin, College Green, \\ Dublin 2, Ireland \\ *E-mail: melyons@tcd.ie, brownem6@tcd.ie
}

doi: $10.20964 / 2016.08 .38$

Received: 13 May 2016 / Accepted: 2 June 2016 / Published: 7 July 2016

\begin{abstract}
In this study, nickel oxide films were prepared through an electrodeposition technique. NiO films were fabricated on Indium Tin Oxide (ITO) supports by cycling the potential between two different sets of limits. The electrodeposition technique which involved using the shorter potential limits was denoted as deposition process 1 and the technique using the wider potential limits was called deposition process 2. Subsequently, the films fabricated by the two deposition process were evaluated as electrochromic materials. The results show that the Colouration Efficiency (CE) values achieved for the deposition process 1 and 2 were $49 \mathrm{~cm}^{2} \mathrm{C}^{-1}$ and $10 \mathrm{~cm}^{2} \mathrm{C}^{-1}$, respectively. The switching times of the film made by the first deposition process were also calculated, as this film showed improved electrochromic capabilities. The coloration and bleaching switching times for this $\mathrm{NiO}$ film are 5.7 and 7.4 seconds, respectively. The improved electrochromic results for the film fabricated by deposition process 1 may be due to the smaller potential deposition window as it produced a thinner film with no traces of sulphate ions on the film's surface compared to the other $\mathrm{NiO}$ film produced by the second electrodeposition technique. The films are characterized by SEM-EDX, Raman spectroscopy and XPS. The regeneration of the bleach state was shown to be hindered. This may be due to conductive pathways involved in the reduction of the coloured state being blocked. Raman spectroscopy was used to determine the presence of both the $\mathrm{Ni}(\mathrm{OH})_{2}$ and $\mathrm{NiOOH}$ after the reduction event.
\end{abstract}

Keywords: Electrochromic, Nickel Oxide, Electrodeposition, Bleached, Coloured, Raman, XPS.

\section{FULLTEXT}

(C) 2016 The Authors. Published by ESG (www.electrochemsci.org). This article is an open access article distributed under the terms and conditions of the Creative Commons Attribution license (http://creativecommons.org/licenses/by/4.0/). 